\title{
Solution of Fuzzy Transportation Problem using Improved VAM with Roubast Ranking Technique
}

\author{
Surjeet Singh Chauhan(Gonder) \\ Department of Applied Science \\ Chandigarh University, \\ Gharuan, India
}

\author{
Nidhi Joshi \\ Department of Applied Science \\ Chandigarh University, Gharuan, India
}

\begin{abstract}
The present paper attempts to study the solution of Fuzzy transportation problem so as to find the least transportation cost of commodities when supply, demand and cost of the commodities are represented by fuzzy numbers. Panadian[1] and other authors have presented arithmetic operations, alpha level and simple ranking by various other operations. Pandian[1] has obtained some methods for fuzzy transportation problem. This paper proposes a ranking method to find the fuzzy optimal solution of balanced fuzzy transportation problem using trapezoidal fuzzy numbers with improved Vogel's Approximation Method. This algorithm is found to be more efficient than other existing algorithms. The procedure for the solution is illustrated with a numerical example. Further, comparative study among the new algorithm and the other existing algorithms is established by means of sample problem. The advantages of the proposed method over existing methods are also discussed. Moreover, the proposed representation of trapezoidal fuzzy numbers over existing representation are also discussed.
\end{abstract}

\section{MATHEMATICS SUBJECT \\ CLASSIFICATION- 90C08, 90C 90}

\section{Keywords}

Optimization; Fuzzy transportation problem; Ranking technique; Trapezoidal fuzzy number; optimal solution; Improved VAM; Total opportunity cost.

\section{INTRODUCTION}

According to conventional transportation problems it is assumed that decision maker is sure about the precise values of transportation cost, availability and demand of the product. However, in real world applications, all the parameters of the transportation problems may not be known precisely due to uncontrollable factors. This type of imprecise data may not always well represented by random variable selected from a probability distribution. Fuzzy numbers introduced by Zadeh[2] may represent this kind of data. Method of fuzzy decision making, therefore, is needed here. Fuzzy transportation problem (FTP) is the problem of minimizing fuzzy valued objective functions with fuzzy source and fuzzy destination parameters. The balanced condition is both a necessary and sufficient condition for the existence of a feasible solution to the transportation problem. In this paper, the authors attempts to study the solution of Fuzzy Transportation Problem using Improved VAM with Roubast Ranking Technique. In past, Chanas and Kuchta[3] proposed the concept of the optimal solution for the transportation problem with fuzzy coefficients expressed as fuzzy numbers, and developed an algorithm for obtaining the optimal solution. Liu and Kao[4] described a method for solving fuzzy transportation problems based on extension principle. The study concluded that the membership function of the objective value of the equality problem is contained in that of the inequality problem. Saad and Abbas [5] discussed the solution algorithm for solving the transportation problem in fuzzy environment. The method proposed by the authors obtain positive optimal fuzzy transportation cost in most cases. Gani and Razak[6] presented a two stage cost minimizing fuzzy transportation problem in which supplies and demands i.e. transportation cost, availability and demand of the product are trapezoidal fuzzy numbers.

Mathematically a transportation problem can be stated as follows:

minimize

$z=\sum_{i=1}^{m} \sum_{j=1}^{n} c i j x i j$

subject

$\sum_{j=1}^{n} x i j=a i$

$\mathrm{i}=1,2, \ldots \ldots \ldots \ldots \ldots . \mathrm{m}$

$$
\begin{aligned}
& \sum_{i=1}^{m} x i j=b j \quad \mathrm{j}=1,2, \ldots \ldots \ldots \ldots \ldots \ldots, \mathrm{n} \\
& \mathrm{xij} \geq 0 \quad \mathrm{i}=1,2, \ldots \ldots \ldots \ldots \ldots, \mathrm{m} \quad \mathrm{j}=1,2, \ldots \ldots \ldots \ldots \ldots \ldots . ., \mathrm{n}
\end{aligned}
$$

where cij is the cost of transportation of an unit from the $\mathbf{i}^{\text {th }}$ source to the $\mathbf{j}^{\text {th }}$ destination, and the quantity $\mathbf{x i j}$ is to be some positive integer or zero, which is to be transported from the $\mathbf{i}^{\text {th }}$ origin to $\mathbf{j}^{\text {th }}$ destination. An obvious necessary and sufficient condition for the linear programming problem given in (1) to have a solution is that

$$
\sum_{i=1}^{m} a \mathrm{i}=\sum_{j=1}^{n} b j
$$

i.e. assume that total available is equal to the total required. If it is not true, a fictitious source or destination can be added. It should be noted that the problem has a feasible solution if and only if the condition (2) satisfied. Now, the problem is to determine $\mathbf{x}_{\mathbf{i j}}$, in such a way that the total transportation cost is minimum.

In fuzzy environment a transportation problem can be stated as follows:

minimize

$$
\mathrm{z}=\sum_{i=1}^{m} \sum_{j=1}^{n} c^{\sim} i j x i j
$$

subject to

$\begin{array}{lr}\sum_{j=1}^{n} x i j=a^{\sim} I \mathrm{i}=1,2 \ldots \ldots \ldots \ldots \mathrm{m} & \sum_{i=1}^{m} x i j=\mathrm{b}^{\sim} j \\ \mathrm{j}=1,2 \ldots \ldots \ldots \ldots \ldots \mathrm{n} & \mathrm{xij} \geq 0 \quad \mathrm{i}=1, \\ 2, \ldots \ldots \ldots, \mathrm{m} \quad \mathrm{j}=1,2, \ldots \ldots \ldots \ldots \ldots ., \mathrm{n} & \end{array}$


in which the transportation costs $\tilde{\boldsymbol{c}} \ddot{\boldsymbol{i}} \boldsymbol{j}$, supply $\tilde{\boldsymbol{a}} \boldsymbol{i}$ and demand $\boldsymbol{b} \tilde{j}$ quantities are fuzzy quantities. An obvious necessary and sufficient condition for the fuzzy linear programming problem given in (4-5) to have a solution is that

$$
\sum_{i=1}^{m} a^{\sim} i \cong \sum_{j=1}^{n} \mathrm{~b}^{\sim j}
$$

\section{PRELIMINARIES}

\subsection{Fuzzy set}

A fuzzy set is characterized by a membership function mapping element of a domain, space or universe of discourse $X$ to the unit interval $[0,1]$ i.e. $A=\{(x, \mu A(x) ; x \in X\}$, Here $\mu \mathrm{A}: \mathrm{X} \rightarrow[0,1]$ is a mapping called the degree of membership function of the fuzzy set $\mathrm{A}$ and $\mu \mathrm{A}(\mathrm{x})$ is called the membership value of $x \in X$ in the fuzzy set $A$. These membership grades are often represented by real numbers ranging from $[0,1]$.

\subsection{Trapezoidal fuzzy numbers}

A fuzzy number $\tilde{\mathrm{A}}=(\mathrm{a}, \mathrm{b}, \mathrm{c}, \mathrm{d})$ is said to be trapezoidal fuzzy number if its membership function is given by

$$
\mu \tilde{\mathrm{A}}(\mathrm{x})= \begin{cases}0 & x<\mathrm{a} \\ \frac{(x-a)}{(b-a)} & \mathrm{a} \leq x \leq \mathrm{b} \\ 1 & \mathrm{~b} \leq x \leq \mathrm{c} \\ \frac{(d-x)}{(d-c)} & \mathrm{c} \leq x \leq \mathrm{d} \\ 0 & x>\mathrm{d}\end{cases}
$$

\subsection{Properties of Trapezoidal fuzzy number}

i. Trapezoidal fuzzy number $\tilde{\mathrm{A}}=(\mathrm{a}, \mathrm{b}, \mathrm{c}, \mathrm{d})$ is said to be non negative trapezoidal fuzzy number Iff a-c $\geq 0$

ii. A trapezoidal fuzzy number $\tilde{\mathrm{A}}=(\mathrm{a}, \mathrm{b}, \mathrm{c}, \mathrm{d})$ is said to be zero trapezoidal fuzzy number Iff $a=0, b=0$, $\mathrm{c}=0, \mathrm{~d}=0$.

iii. Two trapezoidal fuzzy numbers $\tilde{\mathrm{A}}_{1}=\left(\mathrm{a}_{1}, \mathrm{~b}_{1}, \mathrm{c}_{1}\right.$, $\left.\mathrm{d}_{1}\right)$ and $\widetilde{\mathrm{A}}_{2}=\left(\mathrm{a}_{2}, \mathrm{~b}_{2}, \mathrm{c}_{2}, \mathrm{~d}_{2}\right)$ are said be equal I.e. $\tilde{\mathrm{A}}_{1}=\tilde{\mathrm{A}}_{2}$. Iff $\mathrm{a}_{1}=\mathrm{a}_{2}, \mathrm{~b}_{1}=\mathrm{b}_{2}, \mathrm{c}_{1}=\mathrm{c}_{2}, \mathrm{~d}_{1}=\mathrm{d}_{2}$.

\subsection{Arithmetic Operators for solving}

\section{Trapezoidal fuzzy number}

If $A=\left[\mathrm{a}_{1}, \mathrm{~b}_{1}, \mathrm{c}_{1}, \mathrm{~d}_{1}\right]$ and $B=\left[\mathrm{a}_{2}, \mathrm{~b}_{2}, \mathrm{c}_{2}, \mathrm{~d}_{2}\right]$ two trapezoidal fuzzy numbers then the arithmetic operations on $A$ and $B$ as follows:

Addition $\mathrm{A}+\mathrm{B}=\left(\mathrm{a}_{1}+\mathrm{a}_{2}, \mathrm{~b}_{1}+\mathrm{b}_{2}, \mathrm{c}_{1}+\mathrm{c}_{2}, \mathrm{~d}_{1}+\mathrm{d}_{2}\right)$

Subtraction A-B $=\left(\mathrm{a}_{1}-\mathrm{d}_{2}, \mathrm{~b}_{1}-\mathrm{c}_{2}, \mathrm{c}_{1}-\mathrm{b}_{2}, \mathrm{~d}_{1}-\mathrm{a}_{2}\right)$

Multiplication $\mathrm{A} \cdot \mathrm{B}=\left(\mathrm{t}_{1}, \mathrm{t}_{2}, \mathrm{t}_{3}, \mathrm{t}_{4}\right)$

Where

$t_{1}=$ minimum $\left\{\mathrm{a}_{1} \mathrm{a}_{2}, \mathrm{a}_{1} \mathrm{~d}_{2}, \mathrm{~d}_{1} \mathrm{a}_{2}, \mathrm{~d}_{1} \mathrm{~d}_{2}\right\}$;

$\mathrm{t}_{2}=$ minimum $\left\{\mathrm{b}_{1} \mathrm{~b}_{2}, \mathrm{~b}_{1} \mathrm{c}_{2}, \mathrm{c}_{1} \mathrm{~b}_{2}, \mathrm{c}_{1} \mathrm{c}_{2}\right\}$;

$\mathrm{t}_{3}=\operatorname{maximum}\left\{\mathrm{b}_{1} \mathrm{~b}_{2}, \mathrm{~b}_{1} \mathrm{c}_{2}, \mathrm{c}_{1} \mathrm{~b}_{2}, \mathrm{c}_{1} \mathrm{c}_{2}\right\}$ and

$\mathrm{t}_{4}=\operatorname{maximum}\left\{\mathrm{a}_{1} \mathrm{a}_{2}, \mathrm{a}_{1} \mathrm{~d}_{2}, \mathrm{~d}_{1} \mathrm{a}_{2}, \mathrm{~d}_{1} \mathrm{~d}_{2}\right\}$.

\subsection{Robust Ranking Technique}

Roubast ranking technique which satisfy compensation, linearity, and additivity properties and provides results which are consist human intuition. If a is a fuzzy number then the Roubast Ranking is defined by

$$
\mathrm{R}(\tilde{\mathrm{a}})=\int_{0}^{1} 0.5\left(a_{\alpha}^{L} a_{\alpha}^{U}\right) d \alpha
$$

where $\left\langle a_{\alpha}^{L} a_{\alpha}^{U}\right\rangle$ is the $\alpha$ level cut of the fuzzy number ã and $\left\langle a_{\alpha}^{L} a_{\alpha}^{U}\right\rangle=\{((\mathrm{b}-\mathrm{a})+\mathrm{a}),(\mathrm{d}-(\mathrm{d}-\mathrm{c}) \alpha)\}$

In this paper we use this method for ranking the objective values. The Roubast ranking index $R(\tilde{a})$ gives the representative value of fuzzy number ã.

\subsection{Algorithm for Improved Vogel Approximation Method}

Step 1: Balance the given transportation problem if either (total supply>total demand) or (total supply<total demand).

Step 2: Obtain the TOC matrix. (The TOC matrix is obtained by adding the "row opportunity cost matrix" (row opportunity cost matrix: for each row, the smallest cost of that row is subtracted from each element of the same row) and the "column opportunity cost matrix"

(Column opportunity cost matrix: for each column of the original transportation cost matrix the smallest cost of that column is subtracted from each element of the same column))

Step 3: Determine the penalty cost for each row and column by subtracting the lowest cell cost in the row or column from the next lowest cell cost in the same row or column.

Step 4: Select the rows or columns with the highest three penalty costs (breaking ties arbitrarily or choosing the lowestcost cell).

Step 5: Compute three transportation costs for selected three rows or columns in step 4 by allocating as much as possible to the feasible cell with the lowest transportation cost.

Step 6: Select minimum transportation cost of three allocations in step 5(breaking ties arbitrarily or choosing the lowest-cost cell).

Step 7: Repeat steps 3-6 until all requirements have been meet.

Step 8: Compute total transportation cost for the feasible allocations using the original balanced-transportation cost matrix.

\section{Important Remarks}

The Algorithm will be improved if one adds the following two additional steps for breaking ties

I. If there is a tie in penalty or minimum transportation cost, choose the largest penalty for allocation.

II. If there is a tie in penalty and minimum transportation cost, then calculate their corresponding row opportunity cost value/column opportunity cost value, and select the one with maximum.

\section{NUMERICAL EXAMPLE:}

Consider the following fuzzy transportation problem which is in [9]. All of data in this problem are trapezoidal fuzzy numbers. The example was solved by the method proposed by the authors of this paper. Afterwards, the results obtained are compared with the previous results. 
Table 1

\begin{tabular}{|l|l|l|l|l|l|}
\hline & 1 & 2 & 3 & 4 & Supply \\
\hline 1 & $(1,2,3,4)$ & $(1,3,4,6)$ & $(9,11,12,4)$ & $(5,7,8,11)$ & $(1,6,7,12)$ \\
\hline 2 & $(0,1,2,4)$ & $(-1,0,1,2)$ & $(5,6,7,8)$ & $(0,1,2,3)$ & $(0,1,2,3)$ \\
\hline Demand & $(3,5,6,8)$ & $(5,8,9,12)$ & $(12,15,16,19)$ & $(7,9,10,12)$ & $(5,10,12,17)$ \\
\hline
\end{tabular}

Now, using Roubast Ranking Technique the above fuzzy transportation table is

Table 2

\begin{tabular}{|l|l|l|l|l|l|}
\hline & 1 & 2 & 3 & 4 & Supply \\
\hline 1 & 2.5 & 3.5 & 11.5 & 7.75 & 6.5 \\
\hline 2 & 1.75 & 0.5 & 6.5 & 1.5 & 1.5 \\
\hline 3 & 5.5 & 8.5 & 15.5 & 9.5 & 11 \\
\hline Demand & 7.5 & 5.5 & 3.5 & 2.5 & \\
\hline
\end{tabular}

After applying Improved VAM

$X_{12}=5.5, X_{13}=1, X_{23}=1.5, X_{31}=7.5, X_{33}=1, X_{34}=2.5$, and the total crisp value of the problem is $X_{0}=121$.

Table 3

\begin{tabular}{|c|c|c|c|c|c|}
\hline & 1 & 2 & 3 & 4 & Supply \\
\hline 1 & & $\begin{array}{l}(1,5,6,1 \\
0)\end{array}$ & $\begin{array}{l}- \\
9,0,2,1 \\
1) \\
\end{array}$ & & $(1,6,7,12)$ \\
\hline 2 & & & $\begin{array}{l}(0,1,2, \\
3)\end{array}$ & & $(0,1,2,3)$ \\
\hline 3 & $\begin{array}{l}(5,7,8,1 \\
0)\end{array}$ & & $\begin{array}{l}(-9,- \\
1,3,11)\end{array}$ & $\begin{array}{l}(1,2,3, \\
4)\end{array}$ & $\begin{array}{l}(5,10,12, \\
17)\end{array}$ \\
\hline $\begin{array}{l}\text { Dema } \\
\text { nd }\end{array}$ & $\begin{array}{l}(5,7,8,1 \\
0)\end{array}$ & $\begin{array}{l}(1,5,6,1 \\
0)\end{array}$ & $\begin{array}{l}(1,3,4, \\
6)\end{array}$ & $\begin{array}{l}(1,2,3, \\
4)\end{array}$ & \\
\hline
\end{tabular}

Thus, the fuzzy optimal solution obtained is:

$X^{\sim} 12=(1,5,6,10) ; X^{\sim} 13=(-9,0,2,11) ; X^{\sim} 23=(0,1,2,3) ;$ $X^{\sim} 31=(5,7,8,10)$

$X^{\sim 33}=(-9,-1,3,11) ; X^{\sim 34}=(1,2,3,4)$

Although, the values of the variables as obtained by Pandian et al., are same as what obtain by the authors, but the optimum fuzzy transportation cost by the present method is 121 whereas, as obtained by Panadian method the solution obtained is 132.17 .

\section{CONCLUSION}

In this paper, the transportation costs are taken as fuzzy numbers which are more realistic and general in nature. Moreover, the fuzzy transportation problem of trapezoidal numbers has been transformed into crisp transportation problem using Robust's ranking indices and then obtained the optimal solution using Improved VAM. Numerical examples show that by this method one can have the optimal solution as well as the crisp and fuzzy optimal total cost. This technique can also be used for solving various other problems also like, project schedules, assignment problems, network flow problems etc.

\section{REFERENCES:}

[1] P. Pandian and G. Natarajan. 2010.A new algorithm for finding a fuzzy optimal solution for fuzzy transportation problems, Applied Mathematical Sciences, 4, 79-90.

[2] L.A Zadeh. 1965.Fuzzy sets, information and control, 8, 338-353.

[3] S. Chanas and D. Kuchta 1996.A concept of the optimal solution of the transportation problem with fuzzy cost coefficients, Fuzzy Sets and Systems 82, 299-305.

[4] Liu, Shiang-Tai and Chiang, Kao 2004.Solving fuzzy transportation problems based on extension principle, European Journal of Operational Research, 153, 661674.

[5] O.M. Saad and S.A. Abbas. 2003. A parametric study on transportation problem under fuzzy environment, The Journal of Fuzzy Mathematics , 115-124.

[6] A. Gani and K.A.Razak.2006.Two stage fuzzy transportation problem, Journal of physical sciences, 63 69.

[7] Poonam Shugani, S. H. Abbas, Vijay Gupta.2012.Unbalanced Fuzzy Transportation Problem With Roubast Ranking Technique, Asian Journal of Current Engineering and Maths 1: 3, 94 - 97.

[8] F.L. Hitchcock.1941.The distribution of a product from several sources to numerous localities, Journal of Math. Phys. 20, 224-230.

[9] G.B. Dantzig. 1963.Linear Programming and Extensions, Princeton University Press, Princeton.

[10] Serdar Korukoglu and Serkan Balli.2010.An improved vogel's approximation method for the transportation problem, Mathematical and computational Applications, Article in press.

[11] S. H. Chen. 1985.Operations on fuzzy numbers with function principle,Tamkang Journal of Management Sciences, 6,13-25.

[12] J. L. Riggs and M.S. Inoue.1975. "Introduction to Operation Research and Management. Science", McGraw-Hill, New York. 